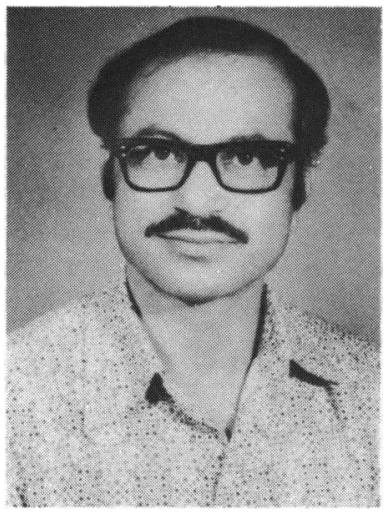

A. K. De

\title{
PHYSICAL EFFICIENCY TESTS ON INDIAN MALE "KABADDI" INTER-UNIVERSITY PLAYERS
}

\author{
A. K. DE, DCH, MD, AFIMS*, P. K. DASGUPTA, BSc, MD*, B. K. PANDA, BSc, MD** \\ and A. K. BHATTACHARYA, MSc, DPhil ** \\ *Unit of Sports Medicine and Pulmonary Physiology, Department of Physiology \\ * *Department of Biophysics, Institute of Medical Sciences, Banaras Hindu University, \\ Varanasi-221005, India
}

\begin{abstract}
Key words: Kabaddi, VC, FEV 1 , MVV, MEFR, PEFR, Grip strength.
\section{INTRODUCTION}

"Kabaddi" is a strenuous outdoor game popular in the Indian subcontinent. It needs a small playing area, 14 players ( 7 on each side) take part at a time and needs no equipment whatsoever. The field area needed for this game is $12.5 \mathrm{~m} \times 10 \mathrm{~m}$ for adult men; however, for women and children a smaller area is specified. The field area is divided into two equal halves (each of $6.25 \mathrm{mx}$ $10 \mathrm{~m})$, one for the raiders and another for the defenders. The raider takes the maximum possible inspiration and
\end{abstract}

ABSTRACT

The participants of inter-university "Kabaddi" competition showed higher values of height, weight and surface area than average Indian population, indicating better attainment of growth in them. Further, the values of respiratory efficiency tests like, FEV 1, MEFR and PEFR were also observed to be more in these players, probably due to training effect. The grip strength values were high in comparison to those of Indian football goalkeepers and hockey players.

Address for communication:

Dr. A. K. Bhattacharya,

Department of Biophysics,

Institute of Medical Sciences,

Banaras Hindu University,

Varanasi-221005,

India then moves to the other side of the field, uttering a continuous chant "Kabaddi" without any further inspiration, to try to touch one of the defending players. The defenders try to hold the raider within their area and the raider tries to force his way back to his own side without discontinuing the chant. If the raider is able to come back to his area after touching a defender a point is credited to his group and the person touched is put out of the game. On the contrary, the defending group gets a point if they can hold the raider, who then has to drop out. If a player is put out from one side, a player who had earlier been eliminated from the opposite group then rejoins his own side. A person from each group alternately raids the opposite side. This process continues until a team succeeds to put out the entire opposing team.

The successful side is then credited with two additional points (Iona). Thereafter the game restarts with all 
the players on each side. The time of play is $\mathbf{4 0}$ minutes with an interval of 5 minutes. During this period, the group scoring the higher number of points wins the match. This game requires breathing exercise, agility, skill, stamina, courage, power of both lower and upper limbs, presence of mind, intelligence, co-ordination, etc. It is enlisted in the inter-university and inter-state competitions in India, and test matches between the countries of the Indian subcontinent are also played.

Recently, we reported our findings on female "Kabaddi" players regarding some physical efficiency tests (De et al, 1979). Since no study on male kabaddi players is available, the present investigation was undertaken on the participants of the inter-university kabaddi competition to record the norms, as well as to assess the effects of this game on the efficiency level and to use these data for comparison among the participants of this game and other sporting events.

\section{MATERIALS AND METHODS}

Forty-one participants of the 1978 inter-university kabaddi competition, held at Banaras Hindu University, volunteered for this study. Most of them had participated earlier in inter-school and/or inter-district kabaddi competitions. The ventilatory capacity tests were performed with the help of a pen recording spirograph.

Peak expiratory flow rate (PEFR) was determined by using Wright's peak flow meter (BOC, England) and grip strength (GS) was measured by Hand Dynamometer (Anand Agencies, India). The ventilatory volumes are all presented in BTPS.

\section{RESULTS AND DISCUSSION}

In the present study, the ventilatory capacity tests were conducted to assess the physical efficiency of the kabaddi players. The results are shown in Tables I and II. The mean height and weight of the subjects were observed to be higher than those of the average Indian population (Gupta et al, 1979). VC when expressed per unit of height or surface area (SA) was found to be higher than that of the average Indian (Mahajan et al, 1978). However, $\mathrm{VC} / \mathrm{cm}$ of height noted in these subjects was lower than the values obtained for sportsmen taking part in other events (De, 1978; De, 1979).

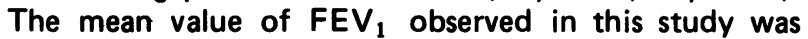
higher than that of physical education students (PES) (De, 1978). This indicates better efficiency in the lung elastic recoil and/or of the respiratory muscles. This might be due to the breathing exercise done by the participants who are accustomed to take maximum inspiration, followed by slow expiration along with the chant during the course of the game. MEFR $(25-75 \%)$ was higher than that reported for healthy male subjects of similar age group (Mahajan et al, 1978) as well as determined for the PES (De, 1978).

MVV is one of the dynamic pulmonary function tests and is dependent upon the speed and efficiency with the filling and emptying of the lungs. The data on MVV reported from various laboratories for healthy Indians vary in magnitude (Mahajan et al, 1978) and are comparable with those observed in the present study. Further, the observed MVV values were similar to those reported for PES (De, 1978). However, the participants from Himachal Pradesh had higher values than the observed mean value of the total group studied. This might be due to the fact that these participants were inhabitants of a hilly area and as such were involved in more strenuous work by going up-hill and down-hill during their daily activities, thereby were more accustomed with the breathing exercise. Similarly, a significantly higher mean value of MVV has been observed in adolescents in the National Cadet Corps from hilly areas compared with those from the plain areas of Uttar Pradesh State (De et al, 1981). The observed mean value of PEFR in this group was higher than those for the average Indians (Gupta et al, 1979; Mahajan et al, 1978; Malik et al, 1975). However, PEFR values of the present investigation were similar to those

\section{TABLE I}

\section{Indian male "Kabaddi" players; Physical characteristics and grip strength of the subjects}

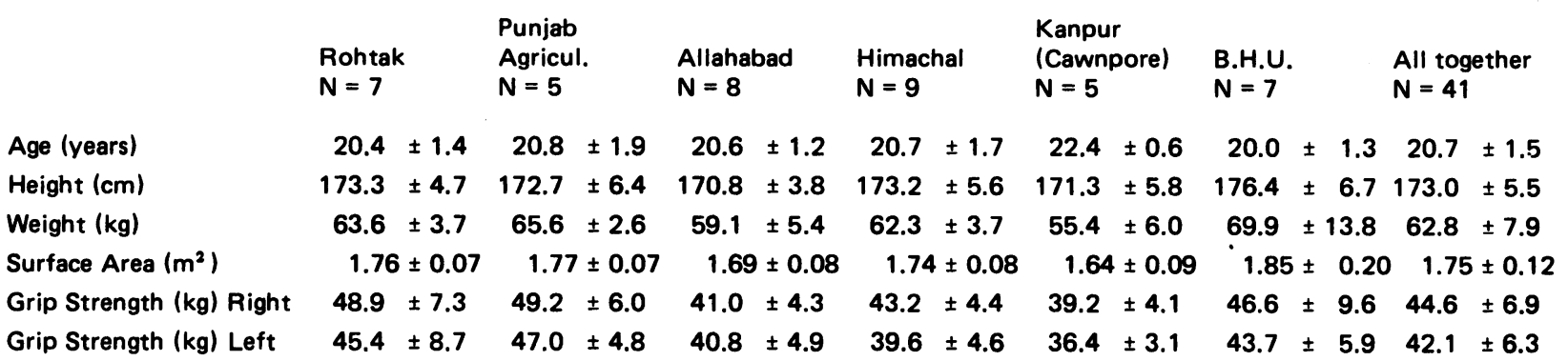

The Values represent Mean \pm Standard Deviation. 
TABLE II

Indian male "Kabaddi" players; Respiratory efficiency

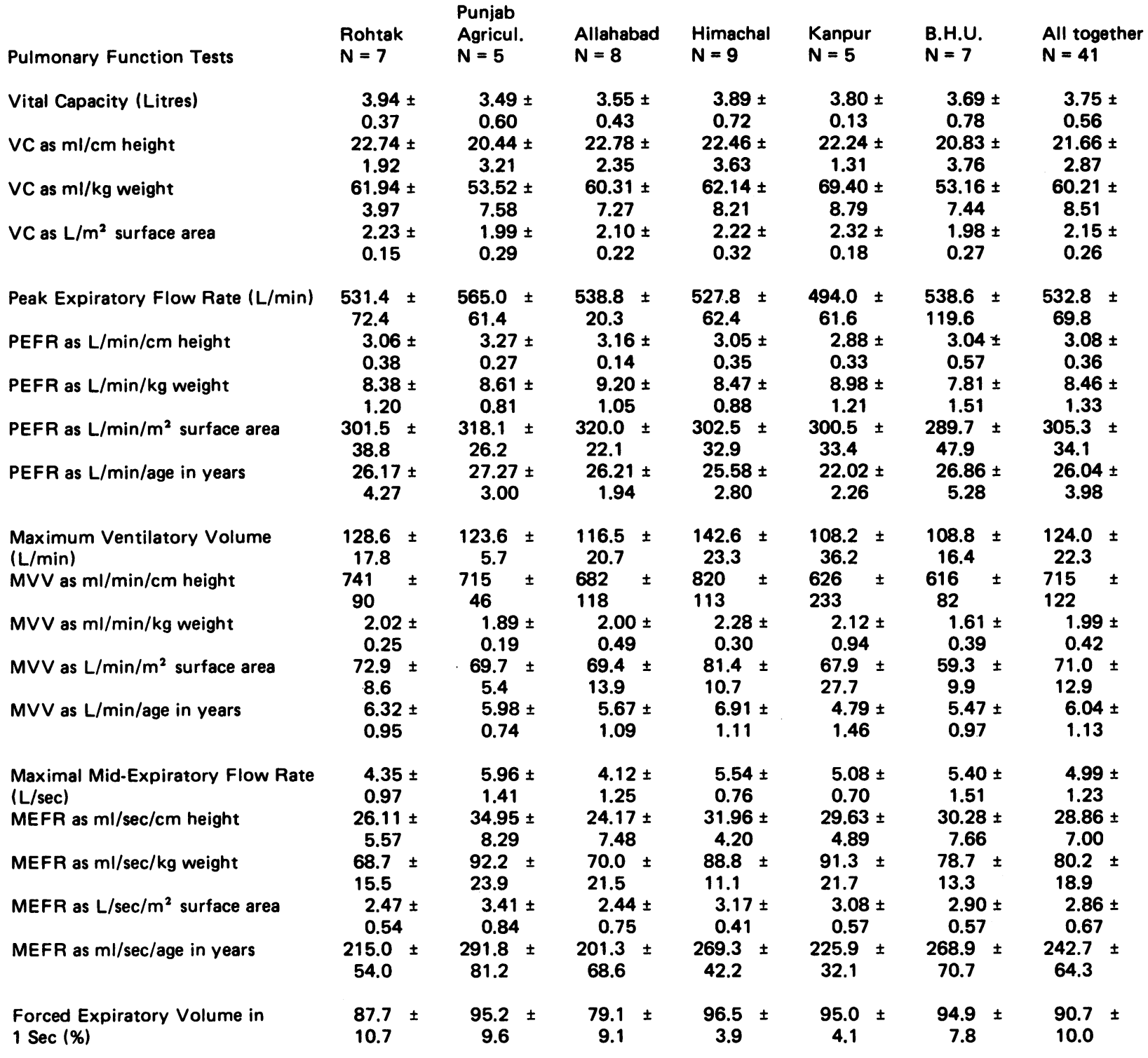

The Values represent Mean \pm Standard Deviation.

reported for Bengalese football goalkeepers (De, 1979) but higher than female kabaddi and volleyball players (De et al, 1979).

The GS values of both the hands were similar to those reported for football goalkeepers (De, 1979) as well as for hockey players (Singh, 1978).

The observed higher values of height, weight, SA,

FEV 1, MEFR and PEFR in these kabaddi players than those of average Indians were probably due to a training effect and to the inherent nature of the game.

\section{ACKNOWLEDGEMENT}

We thank Prof. Karan Singh and Prof. J. Nagchaudhuri of the Banaras Hindu University, for their co-operation and valuable advice. The technical assistance of Mr. R. L. Tripathi, Senior Technical Assistant, is acknowledged. 


\section{REFERENCES}

De, A. K., 1978 "Pulmonary function tests of the students of physical education". J. SNIPES (Soc. Nat.Inst.Physic. Ed. Sports) 1 (1): 74-79.

De, A. K., 1979 "Some efficiency tests on Bengalese football goalkeepers". Brit.J.Sports Med. 13: 173-175.

De, A. K., Debnath, P. K. and Nagchaudhuri, J., 1979 "A comparison of physical efficiency between female volleyball and kabaddi players". J. SNIPES 2 (2): 46-50.

De, A. K., Das Gupta, P. K., Panda, B. K. and Bhattacharya, A. K., 1981 "A comparison of ventilatory pulmonary functions between the National Cadet Corps (NCC) of hilly and plain areas". Indian J.Physiol.Pharmacol. 25: 69-72.

Gupta, Pratibha, Gupta, S. and Ajmera, R. L., 1979 "Lung function tests in Rajasthan subjects". Indian J.Physiol. Pharmacol. 23: 8-14.

Mahajan, K. K., Maini, B. K., Mahajan, S. K., Srivastava, S. C. and Chander, S., 1978 "Pulmonary functions and their correlation with anthropometric parameters in young adults of Haryana (India)". Indian J.Physiol.Pharmacol. 22: 87-92.

Malik, S. K., Jindal, S. K., Jindal, V. and Bansal, S., 1975 "Peak expiratory flow rate in healthy adults". Indian J. Chest Dis. 17: 166-171.

Singh, K., 1978 "Physical fitness of hockey players". J. SNIPES 1 (1): 29-32.

\section{BOOK REVIEW}

Title: PHYSIOLOGICAL CHEMISTRY OF EXERCISE AND TRAINING

Editors:

P. E. di Prampero and J. R. Poortmans

Publisher:

S. Karger, Basel and New York, 1981

Price $\$ 58.75$

60 figures, 22 tables, 219 pages

This is the proceeding of the 1979 Symposium in Fiuggi Terme of the research group on Biochemistry and Exercise, and was sponsored by the International Council of Sports and Physical Education at UNESCO. As with the Sports Sciences book on "The Biochemistry of Exercise", this book is somewhat inevitably out of date for the researcher in the field of sports medicine. Where it differs markedly is that it contains a wealth of practical information for highpowered coaches or athletes on metabolic manipulations to improve marathon running performance, electrolytes, trace elements and vitamins in exercise, a need for supplementation in certain groups, and a statistical treatment of wind assistance and resistance and the possible advantages of shielding behind a front runner by C. T. M. Davies who has written two of the most valuable sections of the book. Indeed all the contributions to this book are by top ranking international experts and are of similarly excellent quality. The more complex topics are presented clearly and the papers are intelligible to a wide range of people which is vital if such a book is to be useful in a multi-disciplinary field such as sports medicine.

I would rate this as an authoritative and useful book for anyone interested in furthering physical performance in sport and promoting scientific techniques in training.

The editors are to be congratulated on the high standard and clarity of this volume.

Malcolm Carruthers, MD, MRCPath, MRCGP 